\title{
Differential Ontogeny of in Vitro Vascular Responses to Three Categories of Calcium Channel Antagonists in Rats ${ }^{1}$
}

\author{
LINDA K. KULLAMA, ${ }^{2}$ VENKATARAMAN BALARAMAN, JOHN R. CLAYBAUGH, \\ WAYNE M. ICHIMURA, BRUCE E. PICHOFF, AND KENNETH T. NAKAMURA \\ Department of Pediatrics, Kapiolani Medical Center for Women and Children and John A. Burns School of \\ Medicine, Honolulu, Hawaii 96826 [L.K.K., V.B., K.T.N.] and Department of Pediatrics and \\ Department of Clinical Investigation, Tripler Army Medical Center, Honolulu, \\ Hawaii $96859-5000$ [J.R.C., W.M.I., B.E.P., K.T.N.]
}

\begin{abstract}
We examined the ontogeny of relaxation responses to three categories of calcium channel antagonists, represented by verapamil, diltiazem, and nifedipine, for both potential-operated (KCl-mediated) and receptoroperated channels [norepinephrine (NE)-mediated] in rat thoracic aorta. Aortic rings from 2- to 3-d, 1-wk, and 12wk-old Sprague Dawley rats were mounted in an organ bath, bathed in Krebs' solution, and connected to a forcedisplacement transducer to measure isometric tension. Endothelium intact vessels at optimal passive force were exposed to a single $\mathrm{ED}_{50}$ of isotonic $\mathrm{KCl}$ or $\mathrm{NE}$, equilibrium contraction was measured, then vessels were washed and exposed for $30 \mathrm{~min}$ to $1 \mu \mathrm{M}$ verapamil, $1 \mu \mathrm{M}$ diltiazem, or $0.1 \mu \mathrm{M}$ nifedipine, followed by another dose of $\mathrm{KCl}$ or $\mathrm{NE}$. Verapamil and diltiazem demonstrated significant $(p<$ 0.05) age-related increases in effectiveness for blocking $\mathrm{KCl}$-mediated contraction [ $\%$ reduction of control contraction \pm SEM) (Verapamil: $2-3 \mathrm{~d}, 67.7 \pm 4.2 ; 1 \mathrm{wk}, 72.5 \pm$ 1.8 ; 12 wk, 89.5 \pm 1.0. Diltiazem: $2-3 \mathrm{~d}, 64.6 \pm 2.9$; 1 wk, $73.5 \pm 3.0 ; 12 \mathrm{wk}, 83.1 \pm 1.8]$. Nifedipine was equally effective at all ages: $2-3 \mathrm{~d}, 85.6 \pm 1.3 ; 1 \mathrm{wk}, 90.0 \pm 1.6$; and $12 \mathrm{wk}, 91.3 \pm 1.4$. Verapamil and diltiazem also showed significant age-related increases in effectiveness for blocking NE-mediated contraction (Verapamil: 2-3 d, $6.2 \pm 3.9 ; 1$ wk, $28.0 \pm 4.8 ; 12$ wk, 44.1 \pm 6.0. Diltiazem $2-3 \mathrm{~d}, 8.0 \pm 3.1 ; 1 \mathrm{wk}, 20.5 \pm 3.9 ; 12$ wk, $46.5 \pm 4.8$ ). Again, nifedipine was equally effective at all ages: $2-3 \mathrm{~d}$, 42.0 $\pm 6.8 ; 1$ wk, $35.8 \pm 3.9$; and 12 wk, $37.5 \pm 3.2$. In summary, for the categories of calcium channel antagonists that interact at the phenylalkylamine (verapamil) and benzothiazepine (diltiazem) binding sites, there were age-related increases in effectiveness for blocking both potentialoperated and receptor-operated channels. However, for nifedipine, which binds to the 1,4-dihydropyridine binding site, no maturational change was observed. These results suggest that the ontogeny of calcium channel antagonists'
\end{abstract}

Received July 12, 1990; accepted October 31, 1990.

Correspondence: Kenneth T. Nakamura, M.D., Department of Pediatrics, Kapiolani Medical Center for Women and Children, 1319 Punahou Street, Rm. 731, Honolulu, HI 96826

Supported by the U.S. Army Health Services Command, The Research Corporation of the University of Hawaii Leahi Trust, and the Research Board, Kapiolani Medical Center. L.K.K is the recipient of an American Heart Association, Hawail Affiliate, Fellowship award.

'The opinions or assertions contained herein are the private views of the authors and are not to be construed as official or as reflecting the views of the Department of the Army or the Department of Defense.

2 Present address: Harbor-UCLA Medical Center, Perinatal Research Laboratories, Departments of Obstetrics and Gynecology and Pediatrics, 1124 West Carson St., RB 1, Torrance, CA 90502 . function may vary depending on the site of binding within the calcium channel. (Pediatr Res 29: 278-281, 1991)

Abbreviations

NE, norepinephrine

POC, potential-operated channels

ROC, receptor-operated channels

$B_{\max }$, receptor density

$\mathbf{K}_{\mathbf{d}}$, receptor affinity

Selective calcium channel antagonists bind to specific sites in the calcium channel. Radioligand binding studies (1-3) indicate three discrete, allosterically linked binding sites for the chemical categories phenylalkylamine, benzothiazepine, and 1,4-dihydropyridine. Selective calcium channel antagonists are represented by the three prototype calcium channel antagonists verapamil, diltiazem, and nifedipine, respectively. Receptor characteristics such as $K_{d}$ and $B_{\max }$ have been shown to be affected by a myriad of factors, including ontogeny (4-7). However, some ontogenic studies have clearly indicated that receptor binding by calcium channel antagonists may be temporally unrelated to calcium channel function. For instance, Renaud et al. (5) demonstrated that nitrendipine (i.e. dihydropyridine) receptors exist in 3-d-old embryonic chick hearts but calcium channels, if present, are not physiologically functional.

We have previously $(8)$ demonstrated the ontogeny of the concentration-dependent response in thoracic aortic rings among 2-d-, 1-wk-, and 12-wk-old rats for both potential-mediated $(\mathrm{KCl}$ induced) and receptor-mediated (NE-induced) contraction. Thus, calcium channel function is present from $2 \mathrm{~d}$ of age with perhaps increasing physiologic function during development. However, many aspects of calcium channel function during ontogeny are unknown. We therefore designed the present study to examine one aspect of calcium channel function, viz. the ontogeny of responses to three categories of calcium channel antagonists for $\mathrm{KCl}$ - and NE-mediated contraction in rat aorta. The objectives were 3-fold: to determine if there were 1 ) agerelated differences in response to selective calcium channel antagonists; 2) differential effects among the three categories of calcium channel antagonists; and 3) differential calcium channel antagonists' effects on POC versus ROC.

\section{MATERIALS AND METHODS}

Adult Sprague-Dawley rats were sedated with an intramuscular injection of $25 \mathrm{mg} / \mathrm{kg}$ ketamine (Vetalar; Parke-Davis, Morris 
Plains, NJ) and killed with an intraperitoneal injection of 250 $\mathrm{mg} / \mathrm{kg}$ thiopental sodium (Pentothal; Abbott Laboratories, Irving, TX). Newborns were killed with an intraperitoneal injection of $1 \mathrm{~g} / \mathrm{kg}$ thiopental. Thoracic aortas were removed from 2- to 3-d- and 6- to 7-d (hereafter referred to as 1-wk)-old rats of either sex and 12-wk-old male rats [respective animal weights: $7.8 \pm$ $0.01 \mathrm{~g}(n=40) ; 13.3 \pm 0.3 \mathrm{~g}(n=53) ;$ and $391.1 \pm 5.3 \mathrm{~g}(n=$ 57)]. Vessels were placed in cold Krebs' solution (containing in $\mathrm{mM}: \mathrm{NaCl} 118, \mathrm{KCl} 4.7, \mathrm{CaCl}_{2} 2.2, \mathrm{MgSO}_{4} 1.2, \mathrm{KH}_{2} \mathrm{PO}_{4} 1.2$, $\mathrm{NaHCO}_{3} 25$, di-sodium EDTA 0.025 , and glucose 11), cleaned of connective tissue, and cut into rings of 4-mm width. Rings were mounted on two fine stainless steel wires that were passed through the lumen and connected to a Grass FT.03 force transducer (Grass Instrument Co., Quincy, MA) coupled to a Gould $2600 \mathrm{~S}$ pen recorder (Gould Inc., Cleveland, $\mathrm{OH}$ ) for continuous measurement of isometric force. Aortas were suspended in an organ bath with $25 \mathrm{~mL}$ of Krebs' solution $\left(37^{\circ} \mathrm{C} ; \mathrm{pH} 7.4\right)$, gassed with $95 \% \mathrm{O}_{2}-5 \% \mathrm{CO}_{2}$, and equilibrated for $60 \mathrm{~min}$ with a bath change every $15 \mathrm{~min}$. Vessels were stretched to the optimal point on their length tension curve determined by equilibrium tension developed to a $\mathrm{ED}_{50}$ of $\mathrm{NE}(8,9)$. Optimal passive forces were: $2-3 \mathrm{~d}, 0.32 \pm 0.01 \mathrm{~g} ; 1 \mathrm{wk}, 0.38 \pm 0.01 \mathrm{~g} ;$ and $12 \mathrm{wk}, 3.2 \pm 0.03$ g. Endothelial function was assessed by observing relaxation upon addition of $10 \mu \mathrm{M}$ acetylcholine to rings preconstricted with a $\mathrm{ED}_{50}$ of NE. All experiments were performed with endothelium-intact vessels.

This study was approved by the Animal Care and Use Committee, Tripler Army Medical Center. Procedures on the rats were in accordance with National Institutes of Health policies and the Guide for the Care and Use of Laboratory Animals (NIH publication no. 85-23, revised 1985).

Preliminary experiments. Before assessing the effects of calcium channel antagonists on single-dose $\mathrm{KCl}$ or NE contractions, it was established that control contractions to both $\mathrm{KCl}$ and $\mathrm{NE}$ were reproducible (time controls). Vessels at optimal passive force were exposed to a single $\mathrm{ED}_{50}$ of isotonic $\mathrm{KCl}$ or $\mathrm{NE}$ and the equilibrium response allowed to develop. Vessels were then washed until optimal passive force was reattained and stabilized. After 30 min in control Krebs', the equilibrium response $\left(R_{2}\right)$ as a percentage of the initial equilibrium response $\left(R_{1}\right)$ was calculated $\left(\mathrm{R}_{2} / \mathrm{R}_{1} \times 100 \%\right): \mathrm{KCl}: 2-3 \mathrm{~d}, 110 \pm 5(n=14) ; 1 \mathrm{wk}, 99$ $\pm 3(n=5) ; 12 \mathrm{wk}, 111(n=2) ; \mathrm{NE}: 2-3 \mathrm{~d}, 109 \pm 3(n=9) ; 1$ wk, $104 \pm 6(n=6) ; 12 \mathrm{wk}, 112 \pm 4(n=6)$.

Because $\mathrm{KCl}$-induced contractions are dependent on extracellular calcium influx, virtually complete blockage of contraction can be obtained with calcium channel antagonists. Residual contraction is due to the hypertonicity induced by cumulative addition of $\mathrm{KCl}$ to obtain the concentration response curve (10). A KCl dose-response curve in the absence (control) and presence of $0.01 \mu \mathrm{M}, 0.1 \mu \mathrm{M}$, and $1 \mu \mathrm{M}$ verapamil is shown in Figure 1 . Very similar results using verapamil in aortas from adult male Wistar rats were reported by Koch et al. (11). These authors also found that both 0.1 and $1 \mu \mathrm{M}$ nifedipine equally inhibited $\mathrm{KCl}-$ induced contraction. For diltiazem, inhibition of intracellular calcium release during NE-induced contraction has been reported (12) for concentrations above $1 \mu \mathrm{M}$. Based on our results and such information in the literature $(11,12)$, doses of calcium channel antagonists selected for this study were $1 \mu \mathrm{M}$ verapamil, $1 \mu \mathrm{M}$ diltiazem, and $0.1 \mu \mathrm{M}$ nifedipine. These doses blocked approximately $90 \%$ of a single isotonic $\mathrm{ED}_{50}$ of $\mathrm{KCl}$ in aortas from 12 -wk-old rats.

Experimental protocol. After a $\mathrm{ED}_{50}$ of either isotonic $\mathrm{KCl}$ ( $\mathrm{NaCl}$ replaced with equimolar $\mathrm{KCl}$ ) or $\mathrm{NE}$, equilibrium control sustained contraction was allowed to develop. Preparations were washed until optimal passive force was reattained and stabilized. Preparations were then exposed for $30 \mathrm{~min}$ to the selected calcium channel antagonist, after which the $\mathrm{ED}_{50}$ of isotonic $\mathrm{KCl}$ or NE was repeated.

Drugs. The following drugs were used: NE, acetylcholine, verapamil, diltiazem (Sigma Chemical Co., St. Louis, MO), and

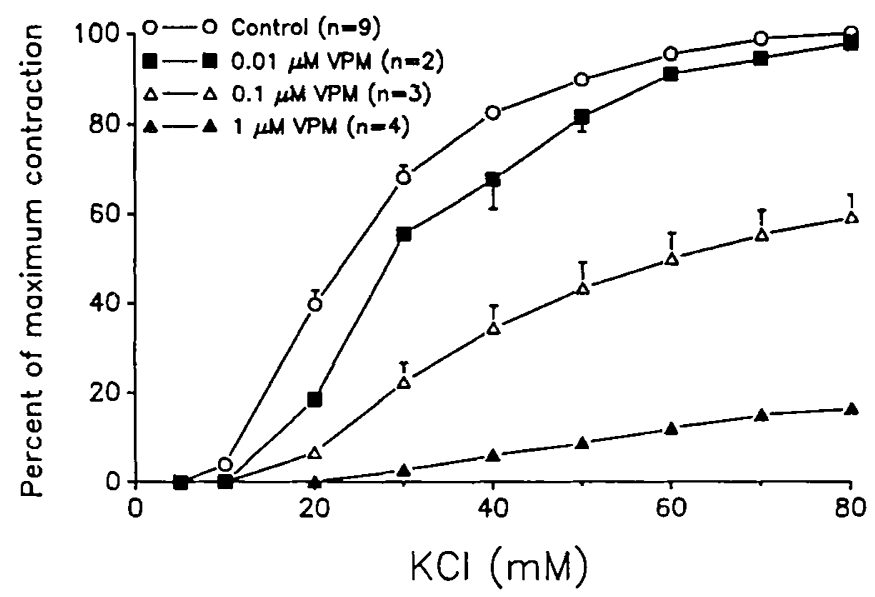

Fig. 1. Effect of verapamil $(Y P M)$ or $\mathrm{KCl}$-induced contraction in 12 wk rat thoracic aortic rings. Values are means $\pm \mathrm{SEM} ; n=$ number of aortic rings.

Table 1. Equilibrium control contraction in rat thoracic aorta*

\begin{tabular}{lccc}
\hline & $2-3 \mathrm{~d}$ & $1 \mathrm{wk}$ & $12 \mathrm{wk}$ \\
\hline $\mathrm{KCl}$ & $0.25 \pm 0.03(21)$ & $0.41 \pm 0.02(23)$ & $2.43 \pm 0.13(26)$ \\
& {$[50 \mathrm{mM}]$} & {$[40 \mathrm{mM}]$} & {$[20-25 \mathrm{mM}]$} \\
$\mathrm{NE}$ & $0.22 \pm 0.02(19)$ & $0.38 \pm 0.02(30)$ & $2.94 \pm 0.11(31) \dagger$ \\
{$[0.03 \mu \mathrm{M}]$} & & &
\end{tabular}

* Units are mean $\mathrm{g} \pm \mathrm{SEM} ;()=$ number of aortic rings; []$=$ dose administered.

† Significant difference between $\mathrm{KCl}$ and $\mathrm{NE}$ at $12 \mathrm{wk}(p<0.05)$.

nifedipine (Pfizer, New York, NY). NE, acetylcholine, verapamil, and diltiazem stock solutions (concentration not $<0.5 \mathrm{mg} /$ $\mathrm{mL}$ ) were made in distilled water and stored at $-20^{\circ} \mathrm{C}$. Nifedipine was dissolved in $100 \%$ ethanol and stored at $-80^{\circ} \mathrm{C}$. Aliquots were freshly diluted daily in distilled water. Each dose was administered in $100-\mu \mathrm{L}$ aliquots, and drug concentrations are expressed as final molar concentration in the bath. Experiments with nifedipine were performed in a darkened room.

Statistical analysis. Two-way analysis of variance with Duncan's multiple range post hoc tests (13) were performed to determine differences among ages and calcium channel antagonists, with $p<0.05$ considered significant. Data are expressed as means \pm SEM.

\section{RESULTS}

Because the amount of induced tone may affect relaxation (14), within each age group we attempted to maintain a relatively constant single-dose control contraction to $\mathrm{KCl}$ and NE. Shown in Table 1 are the control equilibrium contractions with the doses of $\mathrm{KCl}$ and $\mathrm{NE}$ used. For all ages, both isotonic $\mathrm{KCl}$ concentrations (2-3 d, $50 \mathrm{mM} ; 1$ wk, $40 \mathrm{mM} ; 12$ wk, 20-25 $\mathrm{mM})$ and NE concentration $(0.03 \mu \mathrm{M})$ approximated the $\mathrm{ED}_{50}$ values obtained in our previous study (8).

At $2-3 \mathrm{~d}$ and $1 \mathrm{wk}$, we used male and female rats. No significant differences were noted between males and females in percent reduction with any of the three calcium channel antagonists for either $\mathrm{KCl}$ - or NE-induced contraction at either age. For example, percent reduction with verapamil for $\mathrm{KCl}$ was: 2$3 \mathrm{~d}$, female, $66(n=2)$; male, $68 \pm 13(n=5) ; 1 \mathrm{wk}$, female, 71 $\pm 6(n=4)$; male $74 \pm 4(n=4)$. Percent reduction with verapamil for NE was: $2-3 \mathrm{~d}$, female, $6 \pm 10(n=3)$; male, $6 \pm$ $11(n=3)$; 1 wk, female, $28 \pm 18(n=8)$; male, $29 \pm 13(n=$ 5); $p>0.05$.

Effect of verapamil, diltiazem, and nifedipine on $\mathrm{KCl}$-induced contraction (Fig. 2). Both verapamil and diltiazem demonstrated significant age-related increases in effectiveness in blocking $\mathrm{KCl}$ induced contractions. With verapamil, percent reduction of con- 


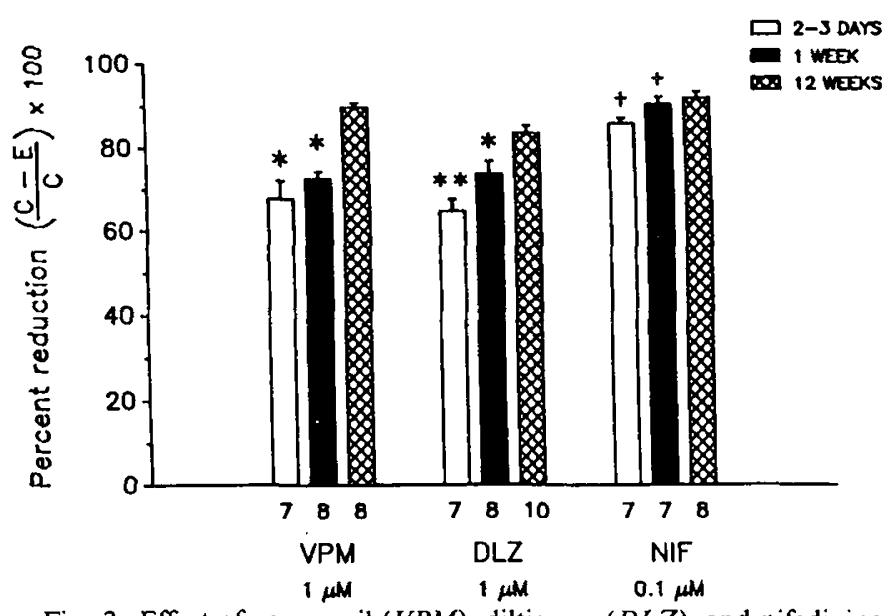

Fig. 2. Effect of verapamil ( $V P M)$, diltiazem $(D L Z)$, and nifedipine (NIF) on KCl-induced contraction in 2- to 3-d, 1-wk, and 12-wk rat thoracic aortic rings. Values are means \pm SEM; numbers under bars = number of rats. *, Significantly less than $12 \mathrm{wk}$, same calcium channel antagonists; ${ }^{* *}$, significantly less than both $1 \mathrm{wk}$ and $12 \mathrm{wk}$, same calcium channel antagonists; + , significantly greater than verapamil and diltiazem, same age (all $p<0.05$ ).

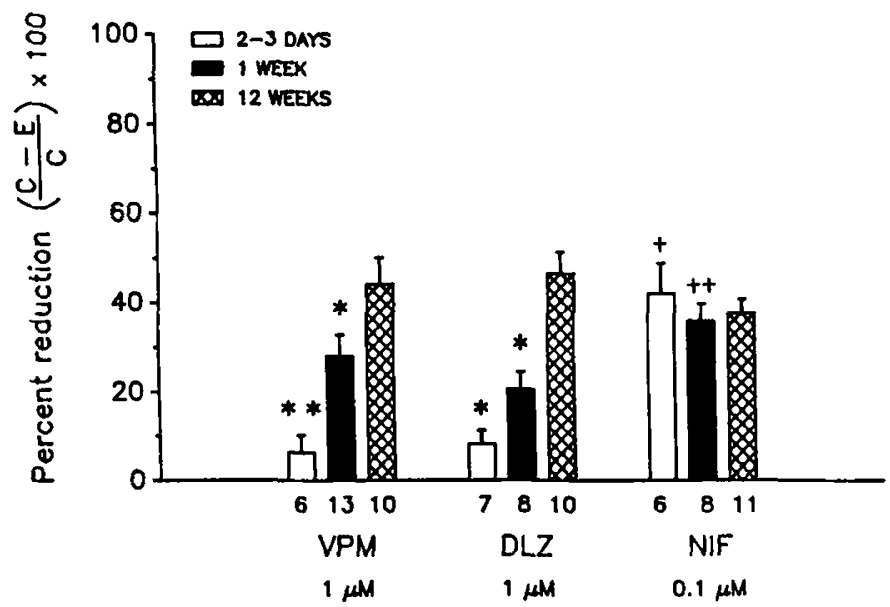

Fig. 3. Effect of verapamil (VPM), diltiazem $(D L Z)$, and nifedipine $(N I F)$ on NE-induced contraction in 2- to 3-d, 1-wk, and 12-wk rat thoracic aortic rings. Values are means \pm SEM; numbers under bars $=$ number of rats. *, Significantly less than $12 \mathrm{wk}$, same calcium channel antagonists; ${ }^{* *}$, significantly less than both $1 \mathrm{wk}$ and $12 \mathrm{wk}$, same calcium channel antagonists; + , significantly greater than verapamil and diltiazem, same age; ++ , significantly greater than diltiazem, same age (all $p$ $<0.05$ ) .

trol contraction at $2-3 \mathrm{~d}$ was $67.7 \pm 4.2 \%$, at 1 wk $72.5 \pm 1.8 \%$, and at $12 \mathrm{wk} 89.5 \pm 1.0 \%$. Similarly, with diltiazem the percent reduction at $2-3 \mathrm{~d}$ was $64.6 \pm 2.9 \%$, at 1 wk $73.5 \pm 3.0 \%$, and at $12 \mathrm{wk} 83.1 \pm 1.8 \%$. There was a significant increase in percent reduction between 2 and $3 \mathrm{~d}$ and 1 wk for diltiazem but not for verapamil and between 1 and $12 \mathrm{wk}$ for both antagonists $(p<$ 0.05 ). On the other hand, nifedipine was equally effective at all ages $(2-3 \mathrm{~d}, 85.6 \pm 1.3 \% ; 1 \mathrm{wk}, 90.0 \pm 1.6 \% ; 12 \mathrm{wk}, 91.3 \pm$ $1.4 \%$ reduction, $p>0.05$ ). In addition, nifedipine was significantly more effective than both verapamil and diltiazem in reducing contraction at 2-3 d and 1 wk $(p<0.05)$.

Effect of verapamil, diltiazem, and nifedipine on NE-induced contraction (Fig. 3). Similar to their effect on $\mathrm{KCl}$-induced contraction, both verapamil and diltiazem demonstrated significant age-related increases in effectiveness in blocking NE-induced contractions. For verapamil, the percent reduction at 2-3 d was $6.2 \pm 3.9 \%$, at 1 wk $28.0 \pm 4.8 \%$, and at $12 \mathrm{wk} 44.1 \pm 6.0 \%$. With diltiazem, the percent reduction at $2-3 \mathrm{~d}$ was $8.0 \pm 3.1 \%$, at 1 wk $20.5 \pm 3.9 \%$, and at 12 wk $46.5 \pm 4.8 \%$. There was a significant increase in percent reduction between 2 and $3 \mathrm{~d}$ and $1 \mathrm{wk}$ for verapamil but not diltiazem, and between 1 and $12 \mathrm{w}$ for both antagonists $(p<0.05)$. In contrast, nifedipine was again equally effective at all ages (2-3 d, $42.0 \pm 6.8 \% ; 1 \mathrm{wk}, 35.8 \pm$ $3.9 \% ; 12 \mathrm{wk}, 37.5 \pm 3.2 \%$ reduction). Nifedipine was significantly more effective than both verapamil and diltiazem in reducing contraction at $2-3 \mathrm{~d}$, and significantly more effective than diltiazem at $1 \mathrm{wk}$ in reducing contraction $(p<0.05)$.

\section{DISCUSSION}

Results herein contribute new and important information regarding the ontogeny of functional responses to calcium channel antagonists. Much of previous work on the influence of age on calcium channel antagonist effects in rat aorta has been on aging $(15,16)$, not ontogeny. Moreover, previous work on ontogeny of calcium channel antagonists has employed radioligand binding studies to examine changes in calcium $K_{d}$ and $B_{\max }$. Studies on perinatal development of ${ }^{3} \mathrm{H}$-nitrendipine (dihydropyridine) binding in several rat tissues indicate that increases in $B_{\max }$ occur without changes in $K_{d}(4)$. Increases in $B_{\max }$ during embryonic development in chick heart (5) and skeletal muscle (6), with an immediate rise in $\mathrm{K}_{d}$ at hatching, have been reported. Although these studies give an indication that changes in binding site characteristics occur during ontogeny, they have not provided insight into the functional physiologic relevance of such changes, particularly in light of studies indicating that receptor binding and calcium channel function may be temporally unrelated (5). However, Hyman et al. (17) examined both dihydropyridine binding site changes and function in the neonatal period and found age-related increases in $B_{\max }$ in isolated cells from rabbit stomach antrum, which is highly dependent on extracellular calcium to support contraction, and an age-related increase in contraction in isolated strips from antrum. These authors found no age-related increase in $B_{\max }$ in the fundus, which utilizes intracellular calcium stores.

Present results demonstrate an increase in sensitivity to two categories of calcium channel antagonists during the same time period in rats when contractile responses to $\mathrm{KCl}$ and $\mathrm{NE}$ are rapidly developing (8). In contrast, results employing a third category of calcium channel antagonists, represented by nifedipine, indicate a different ontogeny than simply a generalized increase in calcium channel antagonists function, inasmuch as nifedipine was equally effective at 2-3 d through $12 \mathrm{wk}$.

Multiple mechanisms may be invoked to explain these observations. For example, these developmental changes may result from alterations in binding site characteristics. Most ontogenic studies of calcium channel antagonists binding sites have been performed using calcium channel antagonists that bind to the dihydropyridine binding site. Binding sites for verapamil and diltiazem are in close proximity, more so than either of them are to the nifedipine (dihydropyridine) binding site, although all three are allosterically linked (18). In fact, Murphy et al. have proposed (19) that all nondihydropyridine calcium channel antagonists act at a single site that is allosterically linked to the dihydropyridine binding site. Later studies, however, have emphasized differences between verapamil and diltiazem binding sites $(1,2)$. No information is available as to the ontogeny of the verapamil and diltiazem binding sites and it is possible that they may differentiate and/or become distinct during ontogeny.

Ontogenic changes in calcium channel antagonists' function may also be due to other factors, such as differential access of calcium channel antagonists to their binding sites. It is of interest to note that both verapamil and diltiazem are classified as "use-" or "state-dependent", i.e. lipid penetration of these ionized drugs through the bilipid membrane is so low that entry to the calcium channel is dependent upon the state of the channel (i.e. open, resting, inactivated), which in turn depends on the membrane potential (20). Although access of neutral dihydropyridines 
such as nifedipine is also voltage-dependent, such compounds, being lipophilic, may reach the calcium channel antagonist binding sites by penetration of the lipid bilayer as well. If access of verapamil and diltiazem to calcium channel antagonist binding sites is state-dependent, age-related alterations in this parameter would presumably affect verapamil and diltiazem similarly and to a greater extent than nifedipine. Thus, functional changes in calcium channel antagonists' effectiveness could occur without concomitant alterations in binding site characteristics.

There remains an ongoing debate as to whether POC and ROC are indeed distinct entities $(10,21)$. Chiu et al. (21) demonstrated in adult rat aorta that both POC and ROC exhibited the same sensitivity to inhibition by calcium channel antagonists (nifedipine and verapamil) of ${ }^{45} \mathrm{Ca}$ influxes and suggested that $\mathrm{POC}$ and ROC in rat aorta share similar structural characteristics, but are gated separately and distinctly by their respective activators. Results herein demonstrate a qualitatively similar pattern of calcium channel antagonist effects between contractions me diated through POC and ROC, supporting the concept that these channels share similar functional and possibly structural characteristics. In addition, our previous work (8), which examined summation effects of POC-and ROC-mediated contractile antagonists, supports the concept of separate and distinct gating mechanisms.

Finally, in addition to agonist effect at the cell membrane, contractile agonist sensitivity to calcium channel antagonists depends also on the extent to which that agonist mobilizes intracellular calcium (22). An expected finding was the reduced overall effectiveness of calcium channel antagonists during NEinduced contraction, which depends in part on intracellular $\mathrm{Ca}^{2+}$, compared to $\mathrm{KCl}$-induced tone at all ages. However, although an age-related change in the ratio of extra/intracellular calcium utilization could explain our results with verapamil and diltiazem, it does not explain the results with nifedipine.

In summary, our results demonstrate that in rat aorta between $2 \mathrm{~d}$ and 12 wks: 1 ) there is a marked ontogeny of increasing responsiveness to the two categories of calcium channel antagonists, represented by verapamil and diltiazem, that are generally classified as use-dependent; 2) the third category of calcium channel antagonists (i.e. nifedipine), however, demonstrates no age-related change in effectiveness; and 3) this pattern is qualitatively similar for both $\mathrm{KCl}$ - and $\mathrm{NE}$-induced contractions.

The clinical use of currently available calcium channel antagonists $(18,23)$ and development of new selective calcium channel antagonists with perhaps new therapeutic indications requires an awareness of basic developmental aspects of calcium channel function. Results herein strongly suggest that the ontogeny of calcium channel antagonist function may vary depending on the site of binding within the calcium channel.

Acknowledgments. The authors thank Dr. E. M. Weiss, Pfizer Laboratories, for the generous supply of nifedipine; Drs. R. A. Hebden and C. F. T. Uyehara for their critical reading of the manuscript; and C. F. T. Uyehara for help with statistical analysis.

\section{REFERENCES}

1. Glossman H, Ferry DR, Goll A. Rombusch M 1984 Molecular pharmacology of the calcium channel: evidence for subtypes, multiple drug-receptor sites. channel subunits, and the development of a radioiodinated 1,4-dihydropyridine calcium channel label, [ ${ }^{125}$ ]iodipine. J Cardiovasc Pharmacol 6:S608S621

2. Garcia ML, King VF. Siegl PKS, Reuben JP, Kaczorowski GJ 1986 Binding of $\mathrm{Ca}^{2+}$ entry blockers to cardiac sarcolemmal membrane vesicles. J Biol Chem. 261:8146-8157

3. Triggle DJ, Janis RA 1987 Calcium channel ligands. Annu Rev Pharmacol Toxicol 27:347-369

4. Kazazoglou T, Schmid A, Renaud J-F, Lazdunski M 1983 Ontogenic appearance of $\mathrm{Ca}$ channels characterized as binding sites for nitrendipine during development of nervous, skeletal, and cardiac muscle systems in the rat. FEBS Lett 164:75-79

5. Renaud J-F, Kazazoglou T, Schmid A. Romey G, Lazdunski M 1984 Differentiation of receptor sites for $\left[{ }^{3} \mathrm{H}\right]$ nitrendipine in chick hearts and physiological relation to the slow $\mathrm{Ca}$ channel and to excitation-contraction coupling. Eur J Biochem 139:673-681

6. Schmid A, Renaud J-F, Fosset M, Meaux J-P. Lazdunski M 1984 The nitrendipine-sensitive $\mathrm{Ca}$ channel in chick muscle cells and its appearance during myogenesis in vitro and in vivo. J Biol Chem 259:11366-11372

7. Godfraind T, Miller R, Wibo M 1986 Calcium antagonism and calcium entry blockade. Pharmacol Rev 38(4):321-416

8. Kullama LK, Balaraman V, Claybaugh JR, Ichimura WM, Nakamura KT 1990 Ontogeny of vasoconstrictor neurohypophysial hormone function in rats. Am J Physiol 258:R263-R268

9. Balaraman V, Kullama LK, Easa D, Robillard JE, Hashiro GM, Nakamura KT 1990 Developmental changes in sodium nitroprusside and atrial natriuretic factor mediated relaxation in the guinea pig aorta. Pediatr Res 27:392395

10. Karaki H, Weiss GB 1988 Calcium release in smooth muscle. Life Sci 42:111122

11. Koch P, Wilhelm D, Wermelskirchen D, Nebel U, Wilfert B, Peters T 1988 Different effects of R 56865 and calcium entry blockers and $\mathrm{K}^{+}$and noradrenaline-induced contractions and ${ }^{45} \mathrm{Ca}$ uptake in rat aorta. Eur J Pharmacol 158:183-190

12. Saida K, van Breeman C 1983 Mechanism of Ca antagonist-induced vasodilation-intracellular actions. Circ Res 52:137-142

13. Winer BJ 1971 Statistical Principles in Experimental Design, 2nd Ed. McGraw Hill, New York

14. Furchgott RF 1983 Role of endothelium in responses of vascular smooth muscle. Circ Res 53(5):557-573

15. Wanstall JC, O'Donnell SR 1988 Inhibition of norepinephrine contractions by dittiazem on aorta and pulmonary artery from young and aged rats: influence of alpha-adrenoceptor reserve. J Pharmacol Exp Ther 245:1016-1020

16. Wanstall JC, O'Donnell SR 1989 Influence of age on calcium entry blocking drugs in rat aorta is spasmogen-dependent. Eur J Pharmacol 159:241-246

17. Hyman PE, Martin MG, Tomomasa T, Jing J, Snape Jr WJ 1989 Development of calcium channels in gastric smooth muscle. Pediatr Res 25:600-604

18. Opie LH 1989 Calcium channel antagonists. Part I, fundamental properties: mechanisms, classification, sites of action. In: Opie LH (ed) Clinical Use of Calcium Channel Antagonist Drugs. Kluwer Academic Publishers, Boston, pp 29-69

19. Murphy KMM, Gould RJ, Largent BL, Snyder SH 1983 A unitary mechanism of calcium antagonist drug action. Proc Natl Acad Sci USA 80:860-864

20. Sanguinetti MC, Kass RS 1984 Voltage-dependent block of calcium channel current in the calf cardiac Purkinje fiber by dihydropyridine calcium channel antagonists. Circ Res 55:336-348

21. Chiu AT, McCall DE, Timmermans PBMWM 1986 Pharmacological characteristics of receptor-operated and potential-operated $\mathrm{Ca}^{2+}$ channels in rat aorta. Eur J Pharmacol 127:1-8

22. Cauvin C, Tejerina M, Hwang O, Kai-Yamamoto M, van Breemen C 1988 The effects of $\mathrm{Ca}^{2+}$ antagonists on isolated rat and rabbit mesenteric resistance vessels. In: Vanhoutte PM, Paoletti R, Govoni S (eds) Calcium Antagonists-Pharmacology and Clinical Research. Annals NY Acad Sci, New York, pp 338-350

23. Cho C, Pruitt AW 1986 Therapeutic uses of calcium channel-blocking drugs in the young. Am J Dis Child 140:360-366 